\title{
Business communication with a graduate as a pedagogical tool in the process of training software users
}

\author{
Anton Detkin ${ }^{1, *}$, Alexander Kobelskiy ${ }^{2}$, and Anastasia Borzova ${ }^{1}$ \\ ${ }^{1}$ V. I. Vernadsky Crimean Federal University, Department of Socio-pedagogical Technologies and \\ Pedagogy of Deviant Behavior, 298600, Simferopol, Russian Federation \\ ${ }^{2}$ Med Inform LLC, Simferopol, Russia
}

\begin{abstract}
Effective achievement of the planned results of the educational process is the most important task of an educational organization. This question is relevant for all levels of education and most types of educational relationships. In some cases, the result of education does not correspond to the planned one. Educational organizations and students have the means to correct such situations both within the educational process and after its completion. The purpose of this study is to evaluate the effectiveness of using the business communication method to achieve the planned educational results after the end of the training process. The study is based on data obtained during an experiment on the use of business communication with 120 graduates of courses on the use of specialized software that make up a representative sample, as well as information about the use of this software by 13883 other users. The results of the study confirm an increase in the achievement of planned educational results, if they were not achieved during the educational process, but the educational organization applied pedagogical communication with the graduate.
\end{abstract}

\section{Introduction}

Educational organizations [1], their graduates [2] and employers of graduates [3] face the problem of discrepancy between expected and actual educational results. Targeted efforts to reduce this discrepancy are often carried out only at the stage of implementation of educational programs $[4,5]$. For this purpose, we use the standardization of educational results [6], measures to monitor the achievement of these results at all stages of the educational process. This approach does not always give a guaranteed result, and some graduates at the beginning of their career are faced with the fact that a number of competencies necessary for work are not formed or are insufficiently formed.

Achieving the planned educational results is also possible at the stage after the completion of the main educational process [7]. In most cases, this is done by the graduate receiving additional education or self-education. The initiator of such actions can be either

* Corresponding author: a.detkin@med-inform.pro 
the graduate himself or the graduate's employer [8]. The initiator can also be an educational organization [9]. This is possible if the educational organization knows that the graduate has not actually achieved the required educational result $[10,11]$. Obtaining such information requires the organization to purposefully study the level and quality of application of the acquired competencies by the graduate.

An important problem in the work of an educational organization with graduates is also the insufficient level of research of methods and means of interaction with the graduate and his employer. In this study, we consider the effectiveness of using one of these tools direct business communication between an educational organization and a graduate.

Following G. V. Borozdina [12], we consider business communication as a process of interaction in which activities, information and experience are exchanged, which implies the achievement of a certain result, the solution of a specific problem or the implementation of a specific goal.

The purpose of our study was to evaluate the effectiveness of a single application of business communication with a graduate by an educational organization to achieve the planned educational results after the end of the training process.

The hypothesis of the study was the assumption that a single contact of an educational organization with graduates in the form of business communication can be a factor that affects the increase in the level of achievement of educational results.

To achieve this goal, the following tasks were performed:

1. a methodology for applying business communication of an educational organization with graduates was developed.

2. an experiment was conducted on the use of business communication between an educational organization and graduates of short-term educational Programs.

3. the analysis of achievement of educational results by graduates depending on the presence of interaction with the educational organization is made.

The methodological basis of the study was the work of G. V. Borozdina [12], I. Y.and E. G. Skibitsky [13].

\section{Research methods and results}

In April 2020, we trained 120 doctors working in medical organizations of the Republic of Crimea on the topic "Working in an automated workplace of a diagnostic doctor". The training was aimed at mastering the basic skills of working in a section of the medical information system specially designed for this category of employees. The secondary goal of the lesson was to motivate students to apply their skills immediately after graduation. Thus, one of the planned educational outcomes was to start working with software or to intensify such work.

The training process consisted of one lesson lasting 1.5-2 academic hours. Classes were held in groups of 4-6 people. All groups were taught by one teacher according to the same lesson program for all students.

The trainees ' special features were that their workplaces were equipped with computer equipment necessary for using the acquired skills, as well as the absence of administrative compulsion to use these skills.

A month after the training, in may 2020, we conducted an analysis of the students ' use of the skills acquired during the training.

\subsection{Data on the application of skills acquired during training}

The information system used by students allows you to get information about its use by each of the users, including all doctors who have been trained by us. 
We evaluated the practical application of the skills acquired during training by eight indicators:

1. the number of authorizations in the system per month. The number of authorizations equal to the number of working days indirectly shows the regular use of the skills acquired during training. However, the information system requires re-authorization in cases where the user has not performed any actions for a certain period, so we can talk about fragmentary application of skills in cases where the number of authorizations is greater than the number of working days.

2. the amount of time spent in the system per month. Time equal to or greater than the employee's working time is an indicator of the daily demand for the skills acquired by the specialist.

3. the number of information entered about the study. The indicator shows the intensity of the application of the minimum allowable amount of skills in the information system.

4. the number of added research protocols. The research Protocol is the main document that you need to get from the work of a trained specialist. Adding a research Protocol requires more effort from the specialist than just adding information about the study. This is the most important indicator in our study.

5. the number of used templates in research protocols. The use of various research Protocol templates demonstrates the specialist's readiness to find suitable Protocol templates and apply them. This indicator is indirect, since it is limited by the fact that a single Protocol template is sufficient for a number of specialties.

6. the number of added research protocol templates. The indicator demonstrates the willingness of the trained employee to actively develop the variability of skills application, creating new templates of research protocols in accordance with professional needs.

7. the number of documents added based on an assignment created in the system by another employee. The increase in the number of documents created on the basis of the assignment indirectly indicates the readiness of the specialist to interact with their colleagues in the use of the information system and the skills acquired during training.

8. the number of documents added based on the destination received in hard copy. The presence of documents entered on the basis of the handwritten direction indicates a high motivation of the specialist to apply the skills acquired during training.

Thus, eight dependent variables were obtained in our study. Table 1 shows the values of variables for one month from the date of training.

Table 1. Applying skills in the first month of training.

\begin{tabular}{|l|l|l|l|l|l|}
\hline \multicolumn{1}{|c|}{ Variable name } & Unit & $\begin{array}{c}\text { Average } \\
\text { (Avg.) }\end{array}$ & $\begin{array}{c}\text { Standard } \\
\text { deviation } \\
\text { (SD) }\end{array}$ & Min & Max \\
\hline $\begin{array}{l}\text { The number of authorizations in the system per } \\
\text { month }\end{array}$ & Ед & 3,825 & 6,51909 & 0 & 22 \\
\hline The amount of time spent in the system per month & Ч & 11 & 17 & 0 & 54 \\
\hline $\begin{array}{l}\text { The number of information entered about the } \\
\text { study }\end{array}$ & Ед & 69 & 117 & 0 & 344 \\
\hline The number of added research protocols & Ед & 54 & 104 & 0 & 304 \\
\hline $\begin{array}{l}\text { The number of used templates in research } \\
\text { protocols }\end{array}$ & Ед & 0,7 & 1,1 & 0 & 4 \\
\hline The number of added research protocol templates & Ед & 0 & 0 & 0 & 0 \\
\hline $\begin{array}{l}\text { The number of documents added based on an } \\
\text { assignment created in the system by another } \\
\text { employee }\end{array}$ & Ед & 68 & 117 & 0 & 342 \\
\hline $\begin{array}{l}\text { The number of documents added based on the } \\
\text { destination received in hard copy }\end{array}$ & Ед & 0,75 & 0,972 & 0 & 2 \\
\hline
\end{tabular}


Initial statistics indicate a low level of use of the skills acquired during training. One of the reasons for these values is the lack of requirements from the administrations of medical organizations to use the information system, i.e. to implement the skills that were obtained during training. For our research, the current situation is favorable, as it allows us to show the influence of business communication on the use of skills in a relatively pure form.

\subsection{Characteristics of contacts with graduates}

The independent variable in our study is business communication between a representative of an educational organization and a graduate. In the study, we used a one-time dialogue with a trained specialist on a given program.

The main features of the business communication used in the study:

1. Business communication is initiated by an educational organization.

2. The participants of the dialogue were a representative of an educational organization and a graduate. Involvement of other persons, such as the graduate's employer, was not applied.

3. Communication is applied exactly one month after the end of training.

4. The dialogue with the student was conducted by the teacher who conducted the training sessions.

5. the content of the dialogue was aimed at clarifying the reasons for non-use or fragmentary use of the information system, as well as demonstrating the possibilities of applying the skills that were acquired during training. The content of the dialog changed slightly depending on the level of skill application in the first month after training.

6. Communication was made by telephone.

7. The duration of the communication ranged from 2 to 10 minutes.

Business communication was applied to half of the trained specialists - 60 graduates. The selection of graduates for the dialogue is made in a random order. Thus, we were able to analyze the impact of a single dialogue with a graduate on the level of application of the skills acquired during training in comparison with a group of graduates with whom communication was not made.

\subsection{Other factors affecting the use of skills}

As control variables that show the degree of influence of business communication with graduates on the level of application of the acquired skills, we used a number of socioeconomic indicators, indicators of workplace equipment, the prevalence of the use of similar skills among colleagues of the graduate, the presence of administrative requirements for the use of skills acquired during training. Table 2 shows the control variables used and their indicators as of the moment of business communication with the graduate.

Table 2. Control variables.

\begin{tabular}{|l|c|c|c|c|}
\hline \multicolumn{1}{|c|}{ Variable name } & Avg. & SD & Min & Max \\
\hline Professional group (doctor, nurse) & 1,7 & 0,5 & 0 & 1 \\
\hline Level of education & 4 & 1 & 3 & 5 \\
\hline $\begin{array}{l}\text { The combination of medical care with the work } \\
\text { of the administrative staff }\end{array}$ & 0,07 & 0,25 & 0 & 1 \\
\hline $\begin{array}{l}\text { The fact of using other information systems (the } \\
\text { presence of accounts in social networks) }\end{array}$ & 0,7 & 0,45 & 0 & 1 \\
\hline Availability of limited health opportunities & 0 & 0 & 0 & 1 \\
\hline Type of settlement & 0,9 & 0,3 & 0 & 1 \\
\hline Age group & 3 & 1 & 1 & 4 \\
\hline
\end{tabular}




\begin{tabular}{|l|c|c|c|c|}
\hline \multicolumn{1}{|c|}{ Variable name } & Avg. & SD & Min & Max \\
\hline Paul & 2 & 0 & 1 & 2 \\
\hline Marital status & 1 & 1 & 1 & 2 \\
\hline Presence of children & 1 & 0 & 1 & 2 \\
\hline Availability of a job where skills can be applied & 0,9 & 0,301 & 0 & 1 \\
\hline Workplace equipment for applying skills & 0,7 & 0,5 & 0 & 1 \\
\hline $\begin{array}{l}\text { number of active users available in the } \\
\text { Department of the organization where the } \\
\text { graduate Works }\end{array}$ & 7 & 5,8 & 1 & 18 \\
\hline $\begin{array}{l}\text { Whether the company has local regulations that } \\
\text { prescribe the use of skills }\end{array}$ & 0 & 0 & 0 & 0 \\
\hline $\begin{array}{l}\text { Availability of municipal regulations } \\
\text { prescribing the use of skills }\end{array}$ & 0 & 0 & 0 & 0 \\
\hline $\begin{array}{l}\text { Availability of regional and Federal regulations } \\
\text { that prescribe the use of skills }\end{array}$ & 1 & 0 & 1 & 1 \\
\hline
\end{tabular}

\subsection{Impact of contact with a graduate on the level of skills application}

Exactly one month after the business communication with half of the graduates, we analyzed the level of application of the skills acquired during the training. Table 3 shows the performance indicators in the information system during this period.

Table 3. Application of skills in the first month after the training.

\begin{tabular}{|l|c|c|c|c|c|c|c|c|}
\hline \multirow{2}{*}{\multicolumn{1}{|c|}{ Variable name }} & \multicolumn{3}{|c|}{$\begin{array}{c}\text { A group of graduates involved } \\
\text { in business communication }\end{array}$} & \multicolumn{3}{c|}{$\begin{array}{c}\text { A group of graduates who } \\
\text { were not involved in business } \\
\text { communication }\end{array}$} \\
\cline { 2 - 10 } & Avg. & SD & Min & Max & Avg. & SD & Min & Max \\
\hline $\begin{array}{l}\text { The number of } \\
\text { authorizations in the system } \\
\text { per month }\end{array}$ & 6,4 & 5,1 & 0 & 15 & 3,37 & 6,05 & 0 & 26 \\
\hline $\begin{array}{l}\text { The amount of time spent } \\
\text { in the system per month }\end{array}$ & 22,6 & 18,2 & 0 & 46 & 9,28 & 15,86 & 0 & 45 \\
\hline $\begin{array}{l}\text { The number of information } \\
\text { entered about the study }\end{array}$ & 110,9 & 115,6 & 0 & 389 & 82,1 & 140 & 0 & 340 \\
\hline $\begin{array}{l}\text { The number of added } \\
\text { research protocols }\end{array}$ & 107,8 & 113,9 & 0 & 384 & 80,8 & 137,9 & 0 & 335 \\
\hline $\begin{array}{l}\text { The number of used } \\
\text { templates in research } \\
\text { protocols }\end{array}$ & 1,22 & 1 & 0 & 4 & 0,74 & 1,35 & 0 & 4 \\
\hline $\begin{array}{l}\text { The number of added } \\
\text { research protocol templates }\end{array}$ & 0,24 & 0,73 & 0 & 5 & 0,13 & 0,34 & 0 & 1 \\
\hline $\begin{array}{l}\text { The number of documents } \\
\text { added based on an } \\
\text { assignment created in the } \\
\text { system by another } \\
\text { employee }\end{array}$ & 110,3 & 115,3 & 0 & 388 & 81,86 & 139,6 & 0 & 339 \\
\hline $\begin{array}{l}\text { The number of documents } \\
\text { added based on the } \\
\text { destination received in hard } \\
\text { copy }\end{array}$ & 2,68 & 15,689 & 0 & 120 & 0,27 & 0,45 & 0 & 1 \\
\hline
\end{tabular}




\subsection{Checking whether the level of application of skills depends on contact with the educational organization}

An analysis of the indicators shown in tables 1 and 3 shows that the use of business communication in the format described in paragraph 2.2 has led to an intensification of the use of skills acquired during training.

The number of authorizations in the system as a whole for all trained users increased by $25.5 \%$ over the period. In the group of graduates with whom the educational organization interacted, the growth was $68 \%$. In the group of trainees with whom business communication was not carried out, the indicator even fell by $12 \%$.

The amount of time spent in the system for a month increased in the group of all trained $45.45 \%$. All this growth occurred in the group of students who communicated with the educational organization.

The number of research data entered into the information system increased by $39 \%$. Here, growth was observed in both groups of graduates, but also with the predominant role of the experimental group (growth of $74.9 \%$ against $11 \%$ in the control group).

The key indicator - the number of added research protocols - increased by $74 \%$ over the period. In the experimental group, the growth was $252 \%$, in the control group $-26.8 \%$.

The number of research Protocol templates used and the number of research Protocol templates added increased mainly due to the low base value. In General, the growth of the first of these indicators was $42 \%$, in the experimental group $-82 \%$. New templates were added in isolated cases in both groups of graduates.

The increase in the number of documents added based on an assignment created in the system by another employee was $41.1 \%$. For graduates who communicated with an educational organization, it was $76.8 \%$, in the control group $-12.3 \%$.

The greatest difference between groups of graduates is seen in the number of documents added based on the assignment received in paper form. In General, this number decreased by $33 \%$ for all graduates. At the same time, an increase of $260 \%$ was observed in the experimental group. It is worth noting that this growth is largely due to the minimum starting values of the indicator.

In addition to the business communication factor, we analyzed the impact on the dependent variables of each of the control variables listed in table 2. it was assumed that these variables may directly or indirectly affect the level of application of skills acquired during training. In our situation, a number of variables have an equal value for all graduates and therefore cannot affect the result of the experiment. Those factors that have different values (gender, age, family status, level of education, etc.) in our study did not show a significant effect on the dependent variables. This effect is probably worth investigating in larger groups of students.

\section{Conclusion and Discussion}

The results of the study showed that business communication is an effective means of working with graduates of educational organizations who have learned to work with software. The study showed that the use of business communication leads to a more active use of the competencies formed during training and, thus, the expected educational results. In our case, growth was observed in each of the eight indicators under consideration.

Thus, the hypothesis put forward about the positive impact of a single contact between an educational organization and a graduate on the achievement of educational results was confirmed.

However, the study has limitations. One of these limitations is the relatively small sample of graduates who participated in the experiment $[14,15]$. 
The second limitation is that the study was conducted on the example of graduates of such educational programs, where the expected result was the active use of the competencies formed during training.

The third restriction is related to the nature of the business communication used. We communicated with graduates once, over the phone, with a pre-defined communication program.

Given these limitations, we can recommend that educational organizations use the method of business communication with graduates in situations where it is known that the graduate did not achieve the educational results that the graduate himself, his employer or educational organization expected.

Business communication with a graduate needs further research. It is necessary to study the impact of regular business communication with a graduate (pedagogical support), to study the effectiveness of different types of business communication and with graduates of different types of educational organizations and educational programs.

\section{References}

1. G. A. Cherednichenko, Educational Studies Moscow, 1, 256-282 (2020)

2. G. I. Davydova, Bulletin of Economic security, 4, 382-385 (2019)

3. S. V. Jungblut, L. A. Butenko, P. P. Kholodov, Coal, 2, 1127 (2020)

4. E. I. Sakharchuk, E. A. Baiykina, Higher education in Russia, 6 (2020)

5. O. V. Korshunova, M. S. Rakipova, Perspectives of Science \& Education, 1, 43 (2020)

6. A. I. Altukhov, M. A. Kvasnikov, A. A. Shekhonin, Higher education in Russia, 3 (2020)

7. M. G. Hudeneva, Modern pedagogical education, 4 (2020)

8. C. Succi, M. Canovi, Studies in Higher Education, 45 (9), 1834-1847 (2020)

9. SS Kathpalia, KKW Ong, AP Leong, RELC Journal, 51 (2), 227-243 (2020)

10. E. A. J. van Hooft, J. D. Kammeyer-Mueller, C. R. Wanberg, R. Kanfer, G. Basbug, Journal of Applied Psychology, Advance online publication (2020)

11. G. Petruzziello, M.G. Mariani, R. Chiesa and D. Guglielmi, Personnel Review, Vol. ahead-of-print No. ahead-of-print. (2020)

12. G. V. Borozdina, Psychology of business communication, 14 (2020)

13. I. Y. Skibitskaya, Business communication, 123 (2020)

14. M. J. Kolen, Applied Measurement in Education, 33 (1), 77-82 (2020)

15. L. Coroneo, F. Iacone, J Appl Econ, 35, 391-409 (2020) 